\title{
Association of Paraga Consumption and Dietary Lifestyle on Nutritional Status of Commercial Drivers in Ibadan Municipality of Oyo State, Nigeria
}

\author{
ADEPOJU, Oladejo Thomas and Akinbode, Omotayo \\ Department of Human Nutrition, Faculty of Public Health, College of Medicine, University of Ibadan, Ibadan 23402, Nigeria
}

\begin{abstract}
The use of herbal products is increasing in trend globally, with over $75 \%$ of the world population using them. In Nigeria, these drinks are popular in many neighbourhoods and sold by vendors in motor parks where commercial drivers have access to them. Though they may have some beneficial effects, they are not completely harmless. This study was carried out to assess the association of Paraga (herbal mixture) consumption and dietary lifestyle on the nutritional status of commercial motor drivers in Ibadan municipality. This descriptive cross-sectional study was carried out among four hundred and twenty-two (422) commercial drivers randomly selected from the five local government areas that make up Ibadan municipality. A structured questionnaire was used to collect data from the respondents. Descriptive statistics and Chi square test were carried out on the data obtained at 5\% level of significance. There was a high prevalence of Paraga consumption among the respondents. There was inadequate nutrient intake among the respondents for most nutrients considered. The nutritional status measurement of the respondents revealed that $4.5 \%$ were underweight, $59.6 \%$ had normal weight, $26.8 \%$ were overweight, while $9.1 \%$ were obese. There was no significant association between Paraga consumption and nutritional status of respondents $(p>0.05)$. However, a significant association was observed between dietary lifestyle pattern and nutritional status of respondents $(p<0.05)$. It is therefore important that commercial drivers be given regular and constant nutrition education during their meetings to help improve their dietary lifestyle. Also, the concerned government agencies/officials should assist in reducing Paraga consumption by helping to reduce alcohol availability at motor parks, and by educational measures to reduce its demand and consumption.
\end{abstract}

Key words: Paraga consumption, dietary pattern, nutritional status, commercial motor drivers.

\section{Introduction}

Medicinal plants have been of great importance to the healthcare needs of individuals and their communities. The use of herbal preparations made from medicinal plants is widespread in developing countries. In local communities where medical care is not so easily accessible due, in part, to lack of healthcare facilities and the high cost of orthodox treatment, recourse to traditional medicine offers the only hope of staying healthy and alive [1, 2].

An estimated $80 \%$ of the developing world population utilize traditional methods of healing which include herbal remedies [3]. In Nigeria, more than $70 \%$ of the

Corresponding author: ADEPOJU, Oladejo Thomas, Ph.D., research field: food nutrition. population depend on traditional remedies for the initial treatment of diseases and injuries $[4,5]$. These herbs are prepared as a mixture of different types of herbs with mostly alcohol or water.

One of the most common herbal preparations being sold among the Yorubas of the South-west Nigeria is Paraga, which has been defined by Oshodi and Aina [6] as "a mixture of unrefined or poorly refined alcohol and herbs which is periodically ingested, as a form of self-medication against certain illnesses”. It is one of the most popular forms in which herbal medicines are dispensed on the street [7] and it is commonly sold by vendors in motor parks where commercial drivers have easy access to them.

Alcohol is a narcotic, an agent that reduces sensation and consciousness, and a central nervous 


\section{Association of Paraga Consumption and Dietary Lifestyle on Nutritional Status of Commercial Drivers in Ibadan Municipality of Oyo State, Nigeria}

system depressant [8]. Hazardous use of alcohol is a public health problem which accounts for about $4.0 \%$ of global disease burden [9]. Also, the World Health Organization has reported a link between drivers' hazardous use of alcohol and road traffic accidents in Nigeria [10]. Alcohol and alcoholic beverage consumption, and cigarette smoking have been found to interfere with nutrient intake, utilization and bioavailability, changing body weight, and basal metabolic rate. The trend of high consumption of alcohol and smoking is common among most road transport workers, as most of them are teenagers and young adults [8].

Commercial drivers (truck, bus and taxi drivers) are reported to be at risk for negative health outcomes due to the unpredictable nature of their profession which expose them to long work hours (up to 14 hours per day), excessive noise, prolonged sitting and unhealthy lifestyles. As a consequence, commercial drivers are at higher risk of adverse health outcomes such as psychological and psychiatric disorders, as well as detriments resulting from disrupted biological cycles, musculoskeletal disorders, cancer and other respiratory morbidities, cardiovascular disease, risk-laden substance use and sexual practices [11]. Also, unhealthy lifestyles such as tobacco use, physical inactivity, and poor diet are very common among commercial drivers.

Smoking, alcohol consumption and unhealthy diet tend to cluster and are all major modifiable contributors to the burden of chronic disease [12]. Tobacco consumers have a higher consumption of alcoholic beverages $[13,14]$ and a lower intake of vegetable and fruit [15].

In Nigeria, not much work has been done or reported on the effect of Paraga consumption and dietary lifestyle of commercial drivers on their nutritional status. Paraga use is believed to be common among drivers, but little information is documented on its use. Information and studies on perceived social benefits and effect of cigarette and alcoholic drinks on nutritional status of drivers in Oyo State and in Nigeria as a whole is minimal and scanty. This study was therefore designed to assess the association between Paraga consumption and dietary lifestyle on the nutritional status of commercial drivers in Ibadan Municipality of Oyo State, Nigeria.

\section{Methodology}

The study was descriptive cross-sectional in design. The five urban local government areas constituting Ibadan municipality LGAs (Ibadan North, Ibadan North-East, Ibadan North-West, Ibadan South-East and Ibadan South-West) were selected for the study. They were stratified into wards, one ward randomly selected, and major operational motor park(s) in each ward was also selected randomly. The respondents interviewed were selected using cluster sample technique. Due to the nature of the job as they are always on the move, it was difficult to meet a very large population of drivers at once in any motor park. A total of four hundred and twenty-two (422) respondents were recruited for the study based on sample size calculation using the formula (FAO [16]):

$$
\mathrm{n}=\frac{\mathrm{Z}^{2}(\mathrm{p})(1-\mathrm{p})}{\mathrm{e}^{2}}
$$

where: $n=$ sample size, $Z=Z$ score value at $95 \%$ confidence interval which is $=1.96, p=$ prevalence at $50 \%$, and $e=$ precision at 0.05 .

A pre-tested, interviewer-administered questionnaire containing different variables such as respondents' personal data, lifestyle pattern and history, feeding pattern, 24-hour dietary recall, anthropometry and WHO methodology for drug survey was used for data collection. Data were analyzed using descriptive statistics and Chi square test, 24-hour dietary recall was analyzed for nutrient adequacy using total dietary assessment (TDA) software, and the level of significance was set at $p<0.05$. Ethical clearance was obtained from the ethical committee of University of Ibadan and University College Hospital (UI/UCH) Institutional Ethical Review Board. Permission and 
written consent were obtained from the unit Chairman in the selected motor parks and study participants respectively.

\section{Results}

\subsection{Socio-Demographic and Socio-Economic Characteristics of Respondents}

Tables 1 and 2 show the socio-demographic and socio-economic characteristics of the respondents. The respondents' age fell within the range 17 and 58 years, with the median age of 35-40 years (22.4\%). Most (89.5\%) of the respondents were Yoruba, 35.1\% had primary level of education, $17.2 \%$ had junior secondary school level certificate, $24.3 \%$ completed secondary school education, while $23.4 \%$ had other levels of education, and $80.0 \%$ were married (Table 1 ). More than half (54.7\%) were taxi drivers, $34.7 \%$ were bus drivers while $10.6 \%$ were bus conductors. Most (97.1\%) of the respondents earned money on daily basis and $94.1 \%$ of them earned more than fifty thousand naira $(\$ 50,000)$ per year on the average. Few (16.5\%) reportedly earned less than one thousand naira per day while $48.4 \%$ earned between one thousand and two thousand naira per day. Less than one-quarter (23.3\%) earned between two and three thousand naira per day, while $11.8 \%$ earned four thousand and above per day (Table 2).

\subsection{Lifestyle Pattern of the Respondents}

Tables 3 and 4 illustrate the lifestyle pattern of respondents. In Table 3, majority (60.9\%) of the respondents reportedly worked for more than 10 hours, $37.2 \%$ worked between 6 and 10 hours, while only 1.9\% worked for 4 hours per day. About three-quarters

Table 1 Socio-demographic and socio-economic characteristics of respondents.

\begin{tabular}{|c|c|c|}
\hline Characteristics & $\mathrm{N}$ & $\%$ \\
\hline \multicolumn{3}{|l|}{ Age } \\
\hline $17-22$ & 24 & 7.6 \\
\hline $23-28$ & 44 & 13.9 \\
\hline $29-34$ & 62 & 19.6 \\
\hline $35-40$ & 71 & 22.4 \\
\hline $41-46$ & 41 & 12.9 \\
\hline $47-52$ & 37 & 11.7 \\
\hline $53-58$ & 38 & 11.9 \\
\hline Total & 317 & 100.0 \\
\hline \multicolumn{3}{|l|}{ Ethnic group } \\
\hline Yoruba & 377 & 89.5 \\
\hline Hausa & 11 & 2.6 \\
\hline Igbo & 14 & 3.3 \\
\hline Ukwani & 2 & 0.5 \\
\hline Edo & 4 & 1.0 \\
\hline Ibibio & 13 & 3.1 \\
\hline Total & 421 & 100.0 \\
\hline \multicolumn{3}{|l|}{ Marital status } \\
\hline Married & 337 & 80.0 \\
\hline Single & 84 & 20.0 \\
\hline Total & 421 & 100.0 \\
\hline \multicolumn{3}{|c|}{ Level of education } \\
\hline Pry education & 147 & 35.1 \\
\hline JSCE & 72 & 17.2 \\
\hline SSCE & 102 & 24.3 \\
\hline Others & 98 & 23.4 \\
\hline Total & 419 & 100.0 \\
\hline
\end{tabular}


Table 2 Socio-economic characteristics of respondents.

\begin{tabular}{|c|c|c|}
\hline Characteristics & $\mathrm{N}$ & $\%$ \\
\hline \multicolumn{3}{|l|}{ Main type of work } \\
\hline Taxi driver & 227 & 54.7 \\
\hline Bus driver & 144 & 34.7 \\
\hline Conductor & 44 & 10.6 \\
\hline Total & 415 & 100.0 \\
\hline \multicolumn{3}{|c|}{ Methods of earning income } \\
\hline On hourly basis & 8 & 1.9 \\
\hline Daily & 403 & 97.1 \\
\hline Weekly & 2 & 0.5 \\
\hline Monthly & 2 & 0.5 \\
\hline Total & 415 & 100.0 \\
\hline \multicolumn{3}{|c|}{ Average earning per year } \\
\hline$<\# 5,000$ & 2 & 0.5 \\
\hline \#5,000- $\$ 10,000$ & 4 & 1.0 \\
\hline$\# 20,000-\# 30,000$ & 14 & 3.6 \\
\hline$>\$ 50,000$ & 375 & 94.9 \\
\hline Total & 395 & 100.0 \\
\hline \multicolumn{3}{|c|}{ Average income per day } \\
\hline$<\# 1,000$ & 67 & 16.5 \\
\hline$\# 1,000-\# 2,000$ & 197 & 48.4 \\
\hline$\# 2,000-\$ 3,000$ & 95 & 23.3 \\
\hline$\$ 4,000-\$ 5,000$ & 26 & 6.4 \\
\hline$>\# 5,000$ & 22 & 5.4 \\
\hline Total & 407 & 100.0 \\
\hline
\end{tabular}

Table 3 Lifestyle pattern of respondents.

\begin{tabular}{lll}
\hline Characteristics & $\mathrm{N}$ & $\%$ \\
\hline Working hours per day & 8 & 1.9 \\
4 hrs & 27 & 6.4 \\
6 hrs & 29 & 6.9 \\
8 hrs & 100 & 23.9 \\
10 hrs & 255 & 60.9 \\
Others & 419 & 100.0 \\
Total & & 25.3 \\
Current tobacco and tobacco products use & 89 & 74.7 \\
Yes & 263 & 100.0 \\
No & 352 & 57.9 \\
Total & & 1.7 \\
Age at first cigarette use & 169 & 14.4 \\
I have never smoked cigarettes & 5 & 26.0 \\
8 years old or younger & 42 & 100.0 \\
between 12 or 15 years old & 76 & 81.4 \\
16 years old or older & 292 & 7.7 \\
Total & & 2.9 \\
Number of cigarettes smoking days in the past 30 days & 276 & \\
$0-7$ days & 26 & \\
8 or 15 days & 10 & \\
16 to 22 days & & \\
\hline
\end{tabular}


Table 3 to be continued

\begin{tabular}{lll}
\hline 23 to 29 days & 7 & 2.1 \\
all 30 days & 20 & 5.9 \\
Total & 339 & 100.0 \\
Number of days of tobacco products use in the last 30 days & & 88.9 \\
$0-7$ days & 303 & 1.8 \\
8 or 15 days & 6 & 3.5 \\
16 to 22 days & 12 & 1.8 \\
23 to 29 days & 6 & 4.0 \\
All 30 days & 14 & 100.0 \\
Total & 341 & \\
\hline
\end{tabular}

Table 4 Lifestyle pattern of respondents (contd.).

\begin{tabular}{|c|c|c|}
\hline Characteristics & $\mathrm{N}$ & $\%$ \\
\hline \multicolumn{3}{|l|}{ Ever consumed a drink that contains alcohol } \\
\hline Yes & 211 & 55.9 \\
\hline No & 146 & 44.1 \\
\hline Total & 357 & 100.0 \\
\hline \multicolumn{3}{|l|}{ Age at first alcohol consumption } \\
\hline Never had a drink of alcohol other than few sips & 89 & 30.8 \\
\hline 8 year old or younger & 6 & 2.1 \\
\hline Between 9 to 15 years & 68 & 23.5 \\
\hline 16 years and older & 126 & 43.6 \\
\hline Total & 289 & 100.0 \\
\hline \multicolumn{3}{|l|}{ Times gotten drunk with alcohol } \\
\hline 0 times & 271 & 77.7 \\
\hline 0 -2 times & 50 & 14.3 \\
\hline 3 times and above & 28 & 8.0 \\
\hline Total & 349 & 100.0 \\
\hline \multicolumn{3}{|c|}{ Number of days of any form of physical activities in the last 30 days } \\
\hline 0-7 days & 120 & 35.5 \\
\hline 8 or 15 days & 32 & 9.5 \\
\hline 16 to 22 days & 53 & 15.7 \\
\hline 23 to 29 days & 7 & 2.1 \\
\hline All 30 days & 126 & 37.2 \\
\hline Total & 338 & 100.0 \\
\hline
\end{tabular}

(74.7\%) of the respondents mentioned non-current use of tobacco and product while $25.3 \%$ indicated current usage. More than half (57.9\%) of respondents reportedly never used cigarette, few (1.7\%) first used cigarette at age 8 years and below, $14.4 \%$, and $26.0 \%$ first used cigarette between 12 and 15 years, and 16 years and above respectively. Majority (81.4\%) reportedly smoked cigarette for only seven days a month, $7.7 \%$ for 8 to 15 days, 2.9\% for between 16 and 22 days, while $5.9 \%$ smoked for the whole 30 days prior to the study. Also, 88.9\% reportedly made use of tobacco products for less than seven days a month, while $1.8 \%, 3.5 \%, 1.8 \%$, and $4.0 \%$ used tobacco products for 8 to 15, 16 to 22, 23 to 29 or 30 days of a month respectively.

In Table 4, 55.9\% of the respondents have ever consumed an alcoholic drink, 30.8\% had ever had a sip, 23.5\% started consuming alcoholic drink between ages 9 and 15 years, while 43.6\% started at age 16 years and above. Majority (77.7\%) of the respondents reported never gotten drunk with alcohol, 14.3\% got drunk within 2 times, while $8.0 \%$ got drunk for 3 or 
more times. More than one-third (35.5\%) of respondents engaged in physical activity for 7 days, 9.5\% for $8-15$ days, $15.7 \%$ for $16-22$ days, while $37.3 \%$ engaged in physical activities throughout the 30 days preceding the study.

\subsection{Beliefs and Practices of Respondents on Paraga Consumption}

Of the 351 respondents (100\%) who responded to interview on Paraga consumption, a total of 199 (56.7\%) confirmed to have taken Paraga while 43.3\% of them claimed never to have taken the alcoholic herbal mixture before (Table 5). About forty-five percent (45.2\%) of these respondents reportedly have not taken the herbal mixture in the past one year, 49.7\% have not taken it in the last 30 days preceding the study, while $22.2 \%, 20.8 \%$, and $7.3 \%$ took it for 1-5 days, 6-19 days and 20 or more days in the month preceding the study respectively. About two-third
(65.2\%) of the respondents took Paraga once daily, $18.7 \%$ took it 2 times/day, while $7.0 \%$ took it 3 to 5 times/day. Many (39.9\%) of the respondents took Paraga any time of the day, $19.2 \%$ took it before work, $25.4 \%$ took it during work, while $15.5 \%$ took it after work.

Of the 199 of respondents who reportedly consume Paraga (Table 5), 173 of them responded to place of consumption of Paraga (Table 6). Of these 173 (100\%) respondents, $37.0 \%$ usually get and consume Paraga in the motor park, $28.2 \%$ did consume it at home, $15.0 \%$ each consumed it at beer parlour and Butakeria, while a total of $4.8 \%$ consumed it elsewhere. Many (22.8\%) of the respondents reportedly consumed Paraga for mental alertness, $18.8 \%$ consumed it for purpose of having energy, while $43.7 \%$ consumed it for treatment of illneses, $7.1 \%$ took it to ward off coldness, $4.1 \%$ consumed it because of its taste while $3.5 \%$ consumed it because others are doing so (Table 6).

Table 5 Beliefs and practices of respondents regarding Paraga consumption.

\begin{tabular}{|c|c|c|}
\hline Characteristics & $\mathrm{N}$ & $\%$ \\
\hline \multicolumn{3}{|l|}{ Ever taken Paraga } \\
\hline No & 152 & 43.3 \\
\hline Yes & 199 & 56.7 \\
\hline Total & 351 & 100.0 \\
\hline \multicolumn{3}{|c|}{ Paraga intake in the past 1 year } \\
\hline No & 151 & 45.2 \\
\hline Yes & 183 & 54.8 \\
\hline Total & 334 & 100.0 \\
\hline \multicolumn{3}{|c|}{ Paraga intake in the last 30 days } \\
\hline No & 170 & 49.7 \\
\hline Yes (1-5 days) & 76 & 22.2 \\
\hline Yes (6-19 days) & 71 & 20.8 \\
\hline Yes (20 or more days) & 25 & 7.3 \\
\hline Total & 342 & 100.0 \\
\hline \multicolumn{3}{|c|}{ Paraga intake in the last 7 days } \\
\hline No & 201 & 58.4 \\
\hline Yes (1-7 days) & 33 & 9.6 \\
\hline Yes (1-5 days) & 16 & 4.7 \\
\hline Yes (2-3 days) & 52 & 15.1 \\
\hline Yes (once a week) & 42 & 12.2 \\
\hline Total & 344 & 100.0 \\
\hline \multicolumn{3}{|l|}{ Paraga intake per day } \\
\hline$>5$ times/day & 17 & 9.1 \\
\hline 5-3 times/day & 13 & 7.0 \\
\hline
\end{tabular}


Table 5 to be continued

\begin{tabular}{lll}
\hline 2 times/day & 35 & 18.7 \\
Once/day & 122 & 65.2 \\
Total & 187 & 100.0 \\
Time of Paraga consumption & & \\
In the morning before work & 37 & 19.2 \\
In the afternoon during work & 49 & 25.4 \\
In the evening after work & 30 & 15.5 \\
Any time of the day & 77 & 39.9 \\
Total & 193 & 100.0 \\
\hline
\end{tabular}

Table 6 Beliefs and practices of respondents regarding Paraga consumption.

\begin{tabular}{lll}
\hline Characteristics & $\mathrm{N}$ & $\%$ \\
\hline Usual place for Paraga consumption & & 37.0 \\
Here in the garage & 64 & 15.0 \\
Beer pallor & 26 & 28.2 \\
At home & 49 & 15.0 \\
Bukateria & 26 & 1.2 \\
Party & 2 & 1.2 \\
Meetings & 2 & 1.2 \\
In my vehicle & 2 & 1.2 \\
Friends place & 2 & 100.0 \\
Total & 173 & \\
Reasons for taking Paraga & & 22.8 \\
To keep alert & 45 & 7.1 \\
To ward-off cold & 14 & 18.8 \\
For more energy & 37 & 3.5 \\
To be like others & 7 & 4.1 \\
Taste is enjoyable & 8 & 43.7 \\
To treat other illness & 86 & 100.0 \\
Total & 197 & \\
\hline
\end{tabular}

\subsection{Nutrient Intake of the Respondents}

The energy (61.8\%), fat (92.2\%), carbohydrate (67.1\%), vitamins A (70.6\%), C (92.4\%), B 6 (53.8\%), and calcium (91.0\%) intakes of most of the respondents were inadequate when compared with the recommended daily allowance (RDA) (Table 7). However, $35.3 \%$ and $46.7 \%$ of the respondents had adequate intake of energy and protein, while $37.9 \%$, $44.1 \%, 39.1 \%$ and $80.8 \%$ had excess intake of vitamins $B_{1}, B_{2}, B_{3}$, and iron respectively when compared with the RDA of each micronutrient.

\subsection{Nutritional Status of the Respondents}

More than half $(59.6 \%)$ of the respondents had normal weight (BMI < 25), 4.5\% were underweight
(BMI < 18.5), 26.8\% were overweight (25 $\leq$ BMI < 30 ), while $9.1 \%$ were obese (Table 8 ).

\subsection{Association between Dietary Lifestyle and Paraga Consumption of Respondents}

There was no significant association between dietary lifestyle and Paraga consumption ( $p>0.05$ ). Table 9 shows that the number of days vegetable was taken has nothing to do with the rate of Paraga consumption, while Table 10 implies that the number of carbonated drinks taken had no association with the rate of Paraga consumption.

3.7 Association between Dietary Lifestyle Pattern and Nutritional Status of Respondents

In Table 11, there was significant association 
Table 7 Nutrient intake of respondents $(n=422)$.

\begin{tabular}{lllll}
\hline Nutrients & Inadequate (\%) & Adequate (\%) & Excess (\%) & Total (\%) \\
\hline Energy & 61.9 & 35.3 & 2.8 & 100 \\
Protein & 23.9 & 46.7 & 29.4 & 100 \\
Fat & 92.2 & 5.9 & 1.9 & 100 \\
Carbohydrate & 67.1 & 27.7 & 5.2 & 100 \\
Vitamin A & 70.6 & 1.7 & 27.7 & 100 \\
Vitamin C & 92.4 & 2.8 & 4.7 & 100 \\
Vitamin $\mathrm{B}_{1}$ & 34.8 & 27.3 & 37.9 & 100 \\
Vitamin $\mathrm{B}_{2}$ & 35.8 & 20.1 & 44.1 & 100 \\
Vitamin $\mathrm{B}_{3}$ & 27.0 & 33.9 & 39.1 & 100 \\
Folate & 45.3 & 29.9 & 24.9 & 100 \\
Vitamin $\mathrm{B}_{6}$ & 53.8 & 21.8 & 24.4 & 100 \\
Calcium & 91.0 & 1.4 & 7.6 & 100 \\
Iron & 4.7 & 14.5 & 80.8 & 100
\end{tabular}

Table 8 Nutritional status of respondents $(n=354)$.

\begin{tabular}{lll}
\hline Nutritional status & $\mathrm{N}$ & $\%$ \\
\hline Underweight & 16 & 4.5 \\
Normal weight & 211 & 59.6 \\
Overweight & 95 & 26.8 \\
Obese & 32 & 9.1 \\
Total & 354 & 100.0 \\
\hline
\end{tabular}

Table 9 Association between dietary lifestyle and Paraga consumption of respondents.

\begin{tabular}{lllll}
\hline \multirow{2}{*}{$\begin{array}{l}\text { No of times vegetable was } \\
\text { taken in the last 30 days }\end{array}$} & \multicolumn{4}{l}{ Range of time Paraga is taken in the last 30 days } \\
\cline { 2 - 5 } None & No & Yes $(1-5$ days $)$ & Yes (6-19 days) & Yes $(\geq 20$ days) \\
$<1$ /day & $86(25 \%)$ & $14(4.1 \%)$ & $8(2.3 \%)$ & $0(0 \%)$ \\
2 x/day & $45(13.2 \%)$ & $48(14 \%)$ & $39(11.4 \%)$ & $11(3.2 \%)$ \\
4 x/day & $8(2.3 \%)$ & $13(3.8 \%)$ & $15(4.4 \%)$ & $12(3.5 \%)$ \\
$\geq 6$ / day & $7(2 \%)$ & $1(0.3 \%)$ & $4(1.2 \%)$ & $0(0 \%)$ \\
Total & $170(49.7 \%)$ & $0(0 \%)$ & $5(1.5 \%)$ & $2(0.6 \%)$ \\
$X^{2}=0.077$ & $p=0.156$ & $76(22.2 \%)$ & $71(20.8 \%)$ & $25(7.3 \%)$ \\
\hline
\end{tabular}

Table 10 Association between dietary lifestyle and paraga consumption of respondents (contd.).

\begin{tabular}{|c|c|c|c|c|}
\hline \multirow{2}{*}{$\begin{array}{l}\text { No of times carbonated drink } \\
\text { was taken in the last } 30 \text { days }\end{array}$} & \multicolumn{4}{|c|}{ Range of time Paraga is taken in the last 30 days } \\
\hline & No & Yes (1-5 days) & Yes (6-19 days) & Yes ( $\geq 20$ days) \\
\hline None & $86(25.2 \%)$ & 35 (10.3\%) & $30(8.8 \%)$ & $16(4.7 \%)$ \\
\hline$<1 /$ day & 75 (22.0\%) & 38 (11.1\%) & 34 (10\%) & $9(2.6 \%)$ \\
\hline 2x/day & $3(0.9 \%)$ & $3(0.9 \%)$ & $4(1.2 \%)$ & $0(0 \%)$ \\
\hline $4 x /$ day & $3(0.9 \%)$ & $0(0 \%)$ & $1(0.3 \%)$ & $0(0 \%)$ \\
\hline$\geq 6 \mathrm{x} /$ day & $2(0.6 \%)$ & $0(0 \%)$ & $2(0 \%)$ & $0(0 \%)$ \\
\hline Total & 169 (49.6\%) & 76 (22.3\%) & 71 (20.8\%) & 25 (7.3\%) \\
\hline$X^{2}$ value $=0.007$ & $p=0.896$ & $\begin{array}{l}\text { Remark = No } \\
\text { significance }\end{array}$ & & \\
\hline
\end{tabular}



Ibadan Municipality of Oyo State, Nigeria

Table 11 Association between dietary lifestyle pattern and nutritional status of respondents.

\begin{tabular}{lllll}
\hline Dietary life style pattern & \multicolumn{4}{l}{ Nutritional status (BMI) } \\
\hline Times food is eaten/day & Underweight & Normal weight & Over-weight & Obese \\
\hline Once & $0(0 \%)$ & $52(17.4 \%)$ & $36(12.1 \%)$ & $21(7.1 \%)$ \\
Twice & $9(3.0 \%)$ & $68(22.8 \%)$ & $30(10.1 \%)$ & $3(1.0 \%)$ \\
Thrice & $5(1.7 \%)$ & $50(16.8 \%)$ & $7(2.3 \%)$ & $5(1.7 \%)$ \\
Other & $2(0.7 \%)$ & $6(2.0 \%)$ & $4(1.3 \%)$ & $0(0.0 \%)$ \\
Total & $16(5.4 \%)$ & $176(59.1 \%)$ & $77(25.8 \%)$ & $29(9.8 \%)$ \\
$X^{2}=43.023$ & $d f=12$ & $p=0.000$ & Remark = Significant & \\
\hline
\end{tabular}

Table 12 Association between Paraga consumption pattern and nutritional status of respondents.

\begin{tabular}{lllll}
\hline Paraga consumption & \multicolumn{3}{l}{ Nutritional status (BMI) } & \\
\hline Times Paraga taken/day & Underweight & Normal weight & Overweight & Obese \\
\hline$>5$ times per day & $2(1.1 \%)$ & $9(4.8 \%)$ & $4(2.1 \%)$ & $2(1.1 \%)$ \\
5 -3 times per day & $1(0.5 \%)$ & $8(4.3 \%)$ & $4(2.1 \%)$ & $0(.0 \%)$ \\
2 times per day & $3(1.6 \%)$ & $22(11.8 \%)$ & $8(4.3 \%)$ & $2(1.1 \%)$ \\
Once per day & $2(1.1 \%)$ & $67(35.8 \%)$ & $37(19.8 \%)$ & $16(8.6 \%)$ \\
Total & $8(4.3 \%)$ & $106(56.7 \%)$ & $53(28.3 \%)$ & $20(10.76 \%)$ \\
$X^{2}=10.569$ & $d f=12$ & $p=0.566$ & Remark $=$ No & \\
\hline
\end{tabular}

between dietary lifestyle pattern and nutritional status of respondents $(p<0.05)$. About seventeen percent (17.4\%) of the respondents that ate once a day were among those who were in the normal weight range, $12.1 \%$ fell into overweight range, while $7.1 \%$ of them were obese. Among respondents that ate twice a day $22.8 \%$ had normal weight, $10.1 \%$ were overweight, and $1.0 \%$ were obese; while $16.8 \%, 2.3 \%$, and $1.7 \%$ of those who ate three times daily had normal weight, overeight and obese respectively. This implies that it is not the number of times food is taken in a day that determines nutritional status but the type of food that is taken at every point in time.

\subsection{Association between Paraga Consumption Pattern and Nutritional Status of Respondents}

There was no significant association between Paraga consumption and nutritional status of respondents (Table 12) $(p>0.05)$. Among those who took Paraga mixture more than five times daily, $4.8 \%$ had normal weight, $2.1 \%$ were overweight, $1.1 \%$ were obese while $1.1 \%$ of were underweight. For those who took it between three to five times a day $10.5 \%$ were underweight, $4.3 \%$ had normal weight, while $2.1 \%$ were overweight. Among those who took it 2 times/day $11.8 \%$ had normal weight, $4.3 \%$ overweight, $1.1 \%$ obese, while $1.6 \%$ were underweight; and for those who took it once daily $35.8 \%$ had normal weight, $19.8 \%$ were overweight, $8.6 \%$ were obese, and $1.1 \%$ were underweight.

\section{Discussion}

Paraga consumption is common among commercial vehicle drivers operating in motor parks in Ibadan municipality. The result obtained in this study for lifetime use prevalence of Paraga by the respondents is higher than the $55.6 \%$ reported by Oluwadiya and Fatoye [7] and 51.6\% recorded amongst secondary school students in Lagos by Oshodi and Aina [6]. The difference between lifetime and current usage prevalence is $11.0 \%$. This is opposed to the findings of Oshodi and Aina (2007), who reported a less than $10.0 \%$ point difference between lifetime and current usage among secondary school students in Lagos. Similarly, Kadiri [17] in a study of Paraga usage in a community in Lagos showed that $60.0 \%$ of Paraga users were taking it on daily basis. The persistent use of Paraga might be 
because the drivers were getting addicted to some of the constituents of the mixture; the most likely constituent being alcohol. Reasons such as "enjoyable taste", "makes me to become more alert" and "makes me gain more energy” point to the presence of alcohol (which is a source of energy) in the mixture, and might be a manifestation of alcohol dependence by the drivers [18]. The consumption of alcohol coupled with smoking was common among the commercial drivers, as most of them were teenagers and young adults. This is in agreement with the findings of McPhillips et al. [19] who reported that cigarette smoking is a highly pervasive personal habit, with a strong appeal among teenagers and young adults.

Inadequate nutrient intake was observed among the respondents for most of the nutrients. The energy, fat and carbohydrate intakes of majority of respondents was inadequate when compared with the RDA. This corroborates the findings of Mustapha et al. [8] who found alcohol to significantly affect the intake of energy-giving nutrients. The inadequate intake may be due to the fact that large intake of alcohol has profound effects on reducing their appetite for nutritious foods because of the high-energy content of alcoholic beverages. However, the protein intake of most of the respondents was adequate. This is consistent with the studies of Ruf et al. [20] and Fawehinmi et al. [21], who found that there were increased intakes observed for animal products among participants who consumed high amount of alcohol. The respondents' inadequate intake for most of the micronutrients observed in this study is in line with the study of Mustapha et al. [8] who reported low intake of micronutrients among road transport workers in Lagos. This may be due to the fact that large intake of alcohol suppresses hunger which reduces food intake and consequently, deprives the body of these essential nutrients.

The result on the nutritional status of the respondents is partially consistent with what was reported by Mustapha et al. [8]. Overweight and obesity result from a caloric imbalance between calories consumed and calories expended. In the USA, when comparing different occupations, obesity rates are highest among motor vehicle operators [22]. This is in line with the findings in this study, considering the level of drivers who are overweight and obese. Commercial drivers remain sedentary for extended periods during the day and have limited options for healthy meals. The combination of physical inactivity and poor diet contributes to the high levels of overweight and obesity among the commercial drivers, though the psychosocial environment may also contribute [23].

No significant association was found between Paraga consumption and nutritional status of the respondents. However, a significant association was observed between dietary lifestyle and nutritional status of the respondents. This indicates that it is not how often diet intake is in a day that determines nutritional status but the type of food and quality of diet that is taken at every point in time. This is in agreement with the work of Pauline et al. [24].

\section{Conclusion}

Commercial drivers operating in motor parks in Ibadan municipality have a high prevalence rate for Paraga usage as it is usually sold within their motor parks. Though no significant association was established between Paraga consumption and nutritional status of the respondents, a significant association was observed between dietary lifestyle and nutritional status of the respondents, which might have been contributed to by the presence of alcohol in the herbal mixture. It was evident from this study that alcohol and alcoholic beverage consumption interfered with energy and nutrients intake of the respondents. Therefore, alcohol and alcoholic beverage consumption should be of public health concern as its consumption over time may predispose the consumers to the development of chronic diseases such as obesity and all its attendant health challenges 


\section{Association of Paraga Consumption and Dietary Lifestyle on Nutritional Status of Commercial Drivers in 225}

Ibadan Municipality of Oyo State, Nigeria

later in life, as well as constituting one of the major causes of road accidents in the country.

\section{Recommendations}

Commercial drivers should be given regular and constant nutrition education during their meetings on the health hazards of Paraga and other alcoholic consumption to help them improve their dietary lifestyle, which will lead to attaining optimal nutritional status. Government officials and agencies as well as non-governmental agencies can assist in reducing Paraga consumption by helping to reduce alcohol availability and through educational measures to reduce its demands. Also, the government and other stakeholders should provide legislation against selling, purchasing, and drinking of narcotics such as cigarette and alcohol in public motor parks and do everything necessary to ensure compliance.

\section{References}

[1] Zhu, M., Lew, K. T., and Leung, P. 2002. "Protective Effect of Plant Formula on Ethanol-Induced Gastric Lesions on Rats.” Phototherapy Research 16: 276-80.

[2] Okochi, V. I., Okpuzor, J., and Alli, L. A. 2003. "Comparison of an African Herbal Formula with Commercially Available Haematinics.” African Journal of Biotechnology 2: 237-40.

[3] World Health Organization. 2002. Traditional Medicine Strategy 2002-2005.

[4] Eniojukan, J., Aina, B., and Alo, A. A. 2000. "Drug Abuse and Self-medication Scenario in Nigeria." The Nigerian Journal of Pharmacy 31: 42-8.

[5] Lambo, T. 2005. "Western and Alternative Medicine: Allies or Foes (Threat).” Nigerian Quarterly Journal of Hospital Medicine 11: 54-7.

[6] Oshodi, O. Y., and Aina, O. F. 2007: “'Paraga' ('Masked Alcohol') Use and the Associated Socio-Cultural Factors among the Yoruba of South West Nigeria: A Case Study of Secondary School Students in Lagos.” Quarterly Journal of Mental Health 1: 1.

[7] Oluwadiya and Fatoye. 2012. “Taking Alcohol by Deception II: Paraga (Alcoholic Herbal Mixture) Use among Commercial Motor Drivers in a South-Western Nigerian City.” BMC Research Notes 5: 301.

[8] Mustapha, R. A., Bolajoko, O. O., Hammed, I. A., and Akinola, O. O. 2012. "Perceived Social Benefits, Effects of Cigarette Smoking and Alcoholic Beverages
Consumption on Nutritional Status of Road Transport Workers in Lagos." IOSR Journal of Pharmacy and Biological Sciences 3 (1): 14-8.

[9] Poznyak, V., Saracemo, B., and Obot, I. S. 2005. "Breaking the Vicious Circle of Determinant and Consequences of Alcohol Use.” Bull World Health Organ 85: 801-80.

[10] World Health Organization. 2009. Global Status Report on Road Safety: Time for Action. Geneva, Switzerland.

[11] Apostolopoulos, Y., Sonmez, S., Shattell, M. M., and Belzer, M. 2010. "Worksite-Induced Morbidities among Truck Drivers in the United States.” AAOHN Journal: Official Journal of the American Association of Occupational Health Nurses 58 (7): 285-96.

[12] Yach, D., Leeder, S., Bell, J., et al. 2005. "Global Chronic Diseases.” Science 307: 317.

[13] Fisher, M., and Gordon, T. 1985. "The Relation of Drinking and Smoking Habits to Diet: The Lipid Research Clinics Prevalence Study.” Am J Clin Nutr 41: 623-30.

[14] Dallongeville, J., Marecaux, N., Fruchart, J. C., and Amouyel, P. 1998. "Cigarette Smoking Is Associated with Unhealthy Patterns of Nutrient Intake: A Meta-Analysis.” J Nutr 128: 1450-7.

[15] Morabia, A., Curtin, F., and Bernstein, M. 1999. "Effects of Smoking and Smoking Cessation on Dietary Habits of a Swiss Urban Population.” Eur J Clin Nutr 53: 239-43.

[16] FAO, Food and Agriculture Organization of the United Nations. 1995. Plant Production and Protection Papers.

[17] Kadiri, A. B. 2008. "Evaluation of Medicinal Herbal Trade (Paraga) in Lagos State of Nigeria." Ethnobotanical Leaflets 1, Article 90.

[18] Edwards, G., and Gross, M. M. 1976. “Alcohol Dependence: Provisional Description of a Clinical Syndrome.” Br Med J. 1: 1058-61.

[19] McPhillips, J. B., Eaton, C. B., Gans, K. M., Derby, C. A., Lasater, T. M., McKenny, J. L., and Carlton, R. A. 1994. "Dietary Differences in Smokers and Non-smokers from Two South Eastern New England Communities.” J Am Diet Assoc. 94 (3): 287-92.

[20] Ruf, T., Nagel, G., Altenburg, H. P., Miller, A. B., and Thorand, B. 2005. "Food and Nutrient Intake, Anthropometric Measurements and Smoking according to Alcohol Consumption in the EPIC Heidelberg Study.” Ann Nutr Metab 49: 16-25.

[21] Fawehinmi, T. O., Ilomäki, J., Voutilainen, S., and Kauhanen, J. 2012. "Alcohol Consumption and Dietary Patterns: The Fin Drink Study.” PLoS ONE 7 (6): e38607. doi:10.1371/journal.pone.0038607.

[22] Caban, A., Lee, D., Fleming, L., Gómez-Marín, O., LeBlanc, W., and Pitman, T. 2005. "Obesity in US Workers: The National Health Interview Survey, 1986 to 
226 Association of Paraga Consumption and Dietary Lifestyle on Nutritional Status of Commercial Drivers in Ibadan Municipality of Oyo State, Nigeria

2002.” American Journal of Public Health 95 (9): 1614-22.

[23] Block, J., He, Y., Zaslavsky, A., Ding, L., and Ayanian, J. 2009. "Psychological Stress and Change in Weight among US Adults.” American Journal of Epidemiology 170 (2): 181-92.
[24] Koh-Banerjee, P., Chu, N. F., Spiegelman, D., Rosner, B., Colditz, G., Willett, W., and Rimm, E. 2003. "Prospective Study of the Association of Changes in Dietary Intake, Physical Activity, Alcohol Consumption, and Smoking with 9-y Gain in Waist Circumference among 16587 US Men.” Am J Clin Nutr. 78: 719-27. 